\title{
Garlic Polyphenols: A Diet Based Therapy
}

\author{
Muhammad Hanif Mughal* \\ Homeopathic Clinic, Islamabad, Pakistan \\ *Corresponding author: Muhammad Hanif Mughal, Homeopathic Clinic, Islamabad, Pakistan
}

\section{ARTICLE INFO}

Received: February 13, 2019

Published: 慧 March 06, 2019

Citation: Muhammad Hanif Mughal. Garlic Polyphenols: A Diet Based Therapy. Biomed J Sci \& Tech Res 15(4)2019. BJSTR. MS.ID.002721.

Abbreviations: DATS: Diallyl Trisulfide; DAS : Diallyl Sulfide; AM : Allyl Mercaptan; DADS: Diallyl Disulfide; EGF: Epidermal Growth Factor; AGE: Aged Garlic Extract; HGE : Heated Garlic Extract; RGE: Raw Garlic Extract

\begin{abstract}
Garlic has been used as medicinal herb due to their therapeutic activities. These activities are linked with presence of bioactive compounds such as diallyl trisulfide (DATS), allicin, diallyl sulfide (DAS), Allyl mercaptan (AM), and diallyl disulfide (DADS). The current review article summarized the chemo-preventive role of garlic along with their bioactive compounds against different human cancers including colon, liver, breast, pancreatic and gastric cancer, pancreatic cancer. They also have been working as to restrain the different cancer stages such as initial, promotion and progression stages. Garlic polyphenols lower the blood glucose level through various pathways such as prevention from the damage of $\beta$-cells, lower the insulin resistance, enhance the insulin sensitivity and secretion, and suppress the activities of glucosidase enzymes. Further, they also suppress the lipid peroxidation, nitric oxide synthetase activity, epidermal growth factor (EGF) receptor, protein kinase c, enzyme activity, survival signaling (IKK, NIK and AKT), NF-kB activity, and cell cycle regulation. In addition, more researchers by the researchers open the new horizons in the field of medicine.
\end{abstract}

Keywords: Garlic, Polyphenols; Allicin; Diallyl Disulfide (DADS); Diabetes Prevention; Antimicrobial

\section{Introduction}

Garlic (Allium sativum L.) belongs to the family Alliaceae and has been derived from the Celtic word 'all' meaning pungent and nature's boon to mankind. More than 5000 years, garlic has been used as curative and food based bioactive agent for physiological disorders. Garlic plant is mentioned in the Ancient Israel (The Talmud), Egypt (Codex Ebers), Bible and India (Vedas and Purans, Charak Sanghita). Chinese people believe that consumption of garlic as diet based therapy is most effective against human metabolic syndromes such as aging, oxidative stress, cancer, wound healing, diabetes, heart diseases and obesity [1]. Hippocrates observed that garlic was inhibited the cancer cells lines and also prevented from the intestinal and extra-intestinal diseases. Prophet Hazrat Mohammad (PBUH) recommended it for treating scorpion stings and cured health's related disorders. In Historia Naturalis by Pliny, it was more effective against dog \& snake bites as well as gastro-intestinal disorders. Allicin is sulfur containing compound formed through the action of alliinase enzyme on alliin and show the anti-platelet and hypolipidemic activity on human health. There are multiple evidences which confirm the uses of garlic as nature tonic to cure diarrhea in ancient times. In Nigeria, it is used to treat diarrhea, abdominal discomfort, respiratory tract, and otitis media infections.

In Europe, India and Pakistan, consumption of garlic was found to cure asthma, hay fever, and common colds, respectively $[2,3]$. Garlic is a promising source of bioactive compounds such as allicin, disulfides, alliin, allyl sulfides, cycloalliin, ajoene, allyl disulfides, methionine, cysteine, cystine, diallyl sulfides, glutathione, pseudoscordinine, dimethyl sulfides, sulfones, allyl trisulfides, thiosulfates, scordinine, methyl sulfides, tetra thiol, trisulfides cysteine, and sulfoxides [4]. It is prominent source of calcium, phosphorous, iron, nicotinic acid, thiamine, riboflavin, and vitamin C, respectively. Garlic comprises of citral, linalool, geraniol, $\alpha$-phellandrene, valeraldehyde, and propionic aldehyde components [5]. They play a significant role against cancer, cataract, cardiovascular disease (CVD), hypercholesterolemia, obesity and hypertension. Maceration of garlic produces oil that good source of 3-vinyl-[4H]-1,2-dithiin, 2-vinyl-[4H]-1,3-dithiin, ajoene and allyl sulfides, whilst steam distillation of garlic oil (SDGO) gives diallyltrisulfide and diallyl disulfide [6] (Tables 1 \& 2). 
Table 1: Nutritional profile of raw garlic/100g

\begin{tabular}{|c|c|c|c|c|c|}
\hline Component & value & Component & Value & Component & Se \\
\hline Energy & $119 \mathrm{kcal}$ & Acidity & $0.172 \%$ & Niacin & $1.02 \mathrm{mg}$ \\
\hline Fat & $0.23 \mathrm{~g}$ & $\mathrm{Ca}$ & $17.8 \mathrm{mg}$ & Riboflavin & $0.02 \mathrm{mg}$ \\
\hline Ash & $2.3 \%$ & $\mathrm{Fe}$ & $1.2 \mathrm{mg}$ & Folic acid & $0.32 \mathrm{mg}$ \\
\hline $\mathrm{Zn}$ & $1.1 \mathrm{mg}$ & $\mathrm{K}$ & $446 \mathrm{mg}$ & Pyridoxine \\
\hline Moisture & $70 \%$ & $\beta$-carotene & $5 \mu \mathrm{g}$ & $\mathrm{I}_{2}$ & $0.7 \mu \mathrm{g}$ \\
\hline Protein & $4.3 \mathrm{~g}$ & $\mathrm{Mg}$ & 24 & Thiamine & $0.16 \mathrm{mg}$ \\
\hline $\mathrm{CH}_{2} \mathrm{O}$ & $24.3 \mathrm{~g}$ & $\mathrm{Na}$ & $19 \mathrm{mg}$ & & \\
\hline Fiber & $1.2 \mathrm{~g}$ & $\mathrm{P}$ & $134 \mathrm{mg}$ & \\
\hline
\end{tabular}

Table 2: Health perspectives of garlic

\begin{tabular}{|c|c|c|c|}
\hline Serial No. & Parameters & Mechanism & Reference \\
\hline 1 & Anticancer & $\begin{array}{l}\text { Induced autophagic cell death } \\
\text { Triggered the production of ROS } \\
\text { Regulated the phosphorylation of p38 MAPK and redox-sensitive JNK1 pathway } \\
\text { Down-regulated the lipid peroxides } \\
\text { Lowered blood glucose level } \\
\text { Suppressed the superoxide formation \& lipid peroxidation } \\
\text { Inhibited the AGEs synthesis } \\
\text { Altered glucose-6-phosphatase, hexokinase and haemoglobin coenzyme-A reductase activity }\end{array}$ & $\begin{array}{l}{[12]} \\
{[13]} \\
{[14,15]} \\
{[26]} \\
{[1]}\end{array}$ \\
\hline 2 & Antimicrobial & $\begin{array}{l}\text { Exhibited antimicrobial activity against E. coli, Salmonella } \\
\text { species }\end{array}$ & [32] \\
\hline 3 & Cardio-protective & $\begin{array}{l}\text { Enhanced fibrinolytic antioxidant activity } \\
\text { Suppressed the angiotensin converting enzyme activity } \\
\text { Reduced the pulse pressure (PP) and improves the pliability of the artery }\end{array}$ & $\begin{array}{c}{[35]} \\
{[36,37]}\end{array}$ \\
\hline 4 & $\begin{array}{l}\text { Blood } \\
\text { coagulation, } \\
\text { Fibrinolysis and } \\
\text { circulatory effects }\end{array}$ & $\begin{array}{l}\text { Enhanced the circulation and blood properties } \\
\text { Increased the fluidity of erythrocytes }\end{array}$ & {$[38,39]$} \\
\hline 5 & Anti-allergic role & $\begin{array}{l}\text { Lowered macrophage infection through induction of nitric oxide (NO) } \\
\text { Inhibition of NF-kappa B activation Inhibitory immunomodulatory effect on intestinal epithelial } \\
\text { cells }\end{array}$ & {$[44]$} \\
\hline
\end{tabular}




\section{Antioxidant Potential of Garlic}

Nencini et al. [7] determined the antioxidant potential of $15 \%$ hydroethanolic extracts of aged diverse parts (bulblets, bulbs, flowers, leaves, and flower bulblets) of Allium subhirsutum L, Allium roseum L. Allium neapolitanum for 20 months. The aged garlic leaves extracts show the higher antioxidant potential followed by flowers and bulbs, whilst bulblets and flower bulblets exhibit no antioxidant potential. Nencini et al. [8] also determined the effect of garlic (bulbs or leaves, $250 \mathrm{mg} / \mathrm{kg}$ ) daily for 5 days in liver of ethanol induced male albino rats. They determined that garlic enhances the GSH and lowers the MDA levels, GR, CAT and SOD activities in liver injury through ethanol. Park et al. [9] evaluated the antioxidant potential garlic extracts through providing different diverse processing conditions. Aged-garlic extract (AGE) yields total phenolic contents (562.6 $\pm 1.92 \mathrm{mg} / 100 \mathrm{~g}$ GAE) as compared to heated garlic extract (HGE) or raw garlic extract (RGE). In H2O2 induced DNA damage of rats, the ED50 $(19.3 \mu \mathrm{g} / \mathrm{mL})$ and inhibition activity $(70.8 \%)$ of aged garlic extract were reported, whereas ED50 value $(38.6 \mu \mathrm{g} / \mathrm{mL})$ of raw garlic extract for 4-hydroxynonenal induced DNA damage followed by aged garlic extract>heated garlic extract was observed. Raw and aged garlic comprises of high quantity of phenolic contents and exhibit high anti-genotoxic activity. They showed chemopreventive role against deleterious effects of $\mathrm{H}_{2} \mathrm{O}_{2}$ against DNA and 4-hydroxy-2,3-trans-nonenal (HNE) [9].

\section{Health Perspectives}

Anticancer Role: Garlic and garlic oil have been found to provide significant protection against $\mathrm{N}$-nitrosodiethylamine-induced hepatocarcinogenesis. Garlic contains fat and water soluble sulfur compounds that exhibits the anti-cancer mechanisms through the ameliorating oxidative stress, improving immune function, and inhibiting metabolic carcinogenic activation [10]. A group of peers, Choi and Park [11] determined that garlic oil has anticancer role by inducing apoptosis, inhibiting differentiation \& tumor angiogenesis and reversing multidrug resistance. Garlic is a potential phytochemical candidate against colon cancer cells, glioblastoma cells and hepato carcinoma cells. It induces apoptosis mechanism in different cancer cells. Allicin, which is the most abundant component in garlic, could induce autophagic cell death in Hep G2 cells [12]. Garlic consists of diallyl disulfide (DADS), diallyl sulfide (DAS), and diallyltrisulfide (DATS) which protect from the carcinogenesis. The supplementation of garlic triggers the production of ROS in glioblastoma cells and induces apoptosis through regulating phosphorylation of p38 MAPK and redox-sensitive JNK1 pathway.

JNK (c-Jun N-terminal kinases) is a potent inhibitor and dominantly lower the cell death by enhancing intracellular free [Ca $(2+)]$, activating caspase- 4 , calreticulin, calpain, caspase- 3 and caspase-9, mitochondrial release of cytochrome $\mathrm{c}$ and Smac into the cytosol, down-regulating $\mathrm{Bcl}^{-2}$, and overexpression of Bax [13]. Garlic dietary phytochemicals inhibit, delay or reverse skin carcinogenesis due to presence of organosulfur compounds i.e. ajoene, allicin,
S-llyl cysteine (SAC) and allyl sulfides. The oral administration of garlic prevents the mice from chemical carcinogen induced skin papillomagenesis [14]. It up-regulates the carcinogenesis progression and down-regulates the lipid peroxides, as well as also modulates PI3K/Akt signaling pathways and the p53 in the skin papilloma cells [15]. Similarly, in another study conducted by Cherng et al. [16], they investigated that supplementation of DAS significantly decreased the expression of apoptotic sunburn cells, proliferative cell nuclear antigen (PCNA), UVB-induced thymine dimer-positive cells, and terminal deoxynucleotidyl transferasemediated dUTP nick end labeling whilst enhanced the p21/Cip1positive cell population and p53 in the epidermis. Moreover, suppression of COX-2, prostaglandin E2 (PGE2), NF- $\kappa$ B, and NO level were reported after DAS administration, respectively [16].

There are different methods like digital rectal examination (DRE) and prostate specific antigen (PSA) use in blood sera and enhance the prostate cancer diagnosis among male population at early stages [17]. The use of androgen drugs suppresses the hormone stimulation of the prostate; on the other side, show deleterious effects on body [18]. Garlic bioactive components inhibit the proliferation of various cancer cells through the histone deacetylase (HDAC) inhibitory activity, down-regulation of the Akt and up-regulation of apoptosis of prostate cancer cells $[19,20]$. The earlier findings of Kim et al. [10] reported that administration of garlic compounds prevented the in vitro and in vivo rats from the prostate cancer. These compounds induced repression of the androgen receptor (AR), apoptosis, and cell cycle arrest in prostate cancer cells. Besides this, they also enhanced the histone acetylation and apoptosis in prostate cancer cells of mice $[21,22]$. The administration of S-allylcysteine at the rate of 1-100 mmol/L in A2780 cells in concentration- and time-dependent fashions momentously suppressed the proliferation of cells. It also induced apoptosis, accompanying by lowering the expression of pro-caspase-3, Parp-1, and Bcl-2, and enhancing active caspase- 3 and Bax. Similarly, it also reduces the migration of A2780 cells, and significantly decreases the protein expression of Wnt5a, p-AKT and c-Jun [23].

Antidiabetic Role: Diabetes is a metabolic disorder and produces the abnormal levels of glucose in the bloodstream. It is growing emerging public health problem and estimated to be 333 million people by 2025 . Herbal plants are being consumed as food by the patient as well as healthy person. Synthetic oral antihypoglycemic agents are more effective to lower the hyperglycaemia level but on other side, they produce the side effects [24]. Allicin is a bioactive component and prevent from the diabetes through lowering the blood glucose level. The oral administration of allicin enhances the free amino acid content and hepatic glycogen, lowers the triglyceride and glucose in serum sucrose-fed rabbits. Similarly, the administration of garlic extracts to streptozotocin-diabetic rats reduced the sugar level, inhibited superoxide formation and lipid per-oxidation. S-allyl cysteine inhibits the AGEs synthesis [25]. DATS, AM, and DAS show the hypoglycemic action that augmented 
the hepatic metabolism, and insulin release [26]. Allicin controls the blood glucose level in serum and alters the activities of liver hexokinase glucose-6-phosphatase and haemoglobin coenzyme-A reductase in rabbits. It significantly increases the free amino acids and liver glycogen that lower the liver serum proteins, triglycerides level (aorta and liver) and fasting blood sugar (FBS) as compared to high sucrose-fed diet rabbits [1].

The supplementation of diallylthiosulfinate and S-methyl cysteine sulfoxide (SMCS) to alloxan diabetic rats that activates 3-hydroxy- 3-methyl-glutaryl (HMG) Co-A reductase, hexokinase, glucose-6-phosphatase, and lecithin- cholesterol acyltransferase (LCAT) enzymes [27]. Padiya et al. [28] also determined the hypoglycaemic effect of garlic that enhanced the insulin sensitivity and lowered the body weight gain in fructose fed rats. The previous findings of Osman et al. [29], they reported that daily intraperitoneal administration of allicin at the rate of $8 \mathrm{mg} / \mathrm{kg}$ diabetic experimental volunteers for 30 days. It effectively reduced the antiislet cell antibodies ICA level through following mechanism (1) the lowered pan B cell marker (CD19), lowered pan T cell marker (CD90), decreased pan innate cells marker (CD11b), prevented from the damage of langerghans islet cell.The hypoglycaemic action of garlic polyphenols could possibly due to release of bound insulin and high pancreatic secretion of insulin from $\beta$-cells. These polyphenols lower the blood glucose level, TG, LDL, VLDL and enhance the HDL level in streptozotocin and alloxan-induced diabetes mellitus rats. S- allyl cysteine restores its function in streptozotocin-diabetic rats by preventing free radicals production through modulating the NADPH oxidase. DAT lowered the fasting blood glucose (FBG), LDL and increased the HDL level in diabetic patients for 12 weeks [30].

Antimicrobial Activity: Antimicrobial drugs have failed to provide response to micro-organisms due to their expensive prices, side effects and greater risk of death [31]. The garlic containing extracts show antimicrobial activity against different types of bacteria such as gram positive (A streptococcus, s. pneumonia group, s. aureus and bacillus anthrax) and gram negative (salmonella species, citrobacter enterobacter, kilabsella and E. coli) [32]. Hindi [33] reported that thiosulfinates in garlic are responsible for the antimicrobial activity in rats. Allicin also exhibits the antibacterial action against some fish pathogenic bacteria. The $10 \% \mathrm{v} / \mathrm{v}$ solution of allicin in dimethyl sulfoxide (DMSO) was also showed anti-bacterial activity against aeromonas veronii, aeromonassobria, aeromonascaviae, aeromonashydrophila and streptococcus iniae. The allicin (MICs; $125 \mu \mathrm{g} / \mathrm{ml}$ ) concentration for aeromonashydrophila and $250-500 \mu \mathrm{g} / \mathrm{ml}$ for aeromonas veronii, aeromonas caviae and aeromonas sobria in dimethyl sulfoxide was found to be effective [34].

Cardiovascular Role: Allicin, DATS, DADS and AM polyphenols perform their antioxidant mechanism and prevent from cardiovascular disease by enhancing fibrinolytic antioxidant activity, inhibiting platelet aggregation, reducting serum lipids and blood pressure levels [35]. The previous findings of Thomson et al. [36] reported that single intravenous dose of garlic extract (10$100 \mathrm{mg} / \mathrm{kg}$ ) dose-dependently suppressed the blood thromboxane B2 concentration in rats. Garlic also up-regulates the cellular glutathione levels in vascular endothelial cells and prevents endothelial dysfunction. The prophylactic supplementation of aged garlic extract prior to ischemia reperfusion suppresses the production of free radicals and prevent from the depletion of glutathione antioxidant enzyme. Similarly, they also suppress the fibrosis development in kidney and liver organs by inhibiting the neutrophil migration. Allicin and DATS suppress the angiotensin converting enzyme activity that lowered the blood pressure and cardio-protective effect in kidney and liver. The aged garlic extract (AGE) reduces the pulse pressure (PP) and improves the pliability of the artery. Additionally, they lower the deleterious effects that produce the papilloma in the forestomach, lower erythrocytes and enhance reticulocytes [37].

Blood Coagulation, Fibrinolysis and Circulatory Effects: In oxidized erythrocytes of rats, the supplementation of aged garlic extract has been found to enhance the blood circulation via preventing hemolysis and lipid peroxidation. Allicin, AM improve the erythrocytes fluidity, whereas unable to protect the erythrocytes from t-butyl hydroperoxide-induced hemolysis [38]. They also modulate the production and function of both constricting factors (endothelin-1) and endothelium-derived relaxing factor (NO) in pulmonary arteries of mice [39]. Garlic juice and g-glutamylcysteines have been proved to show the beneficial effects on heart rate and may lower the blood pressure through inhibiting angiotensin-converting enzyme in vitro [40].

Immunomodulatory Activity: Aged garlic extract, and their bioactive components exhibit the immunomodulatory properties due to presence of organosulfur compounds. The concentration of garlic extract is dominantly effective on IL-2 and INF- $\gamma$ gene expression of stimulated lymphocytes. These compounds also reduce the macrophage infection through the induction of NO production in vitro [41]. Allicin prevents from the immunemediated liver damage of $\mathrm{T}$ cells of mice and as well as also inhibit the NF-kappa B activation. A group of researchers [42], they investigated that allicin supplementation prevented from the intestinal inflammation though inhibitory effect on peripheral blood, and intestinal epithelial cells [42].

Antiallergic Role: Allergic responses are the activation of FceRI receptor on the plasma membrane of mast and basophilic cells is known to liberate the b-hexosaminidase, histamine, cytokines, prostaglandins and leukotrienes allergic mediators. Likewise, arachidonic acid metabolites such as prostaglandins and leukotrienes cause acute and chronic allergic inflammatory reactions [43]. Supplementation of allicin and AM can inhibit the passive cutaneous anaphylaxis (PCA) and immunoglobulin E-mediated aller- 
gic response in RBL-2H3 cells. Similarly, ethyl acetate extract of garlic polyphenols inhibits the release of TNF-a and b-hexosaminidase. They suppress the cPLA2, Syk, COX- 2 and 5-LO factors in rats [44].

\section{Conclusion}

Garlic is mainly used as commodity worldwide for its health promoting perspectives in human such as prevention from cancer insurgence and diabetes, lowering the cardiovascular complications, allergy responses, and aging. Bioactive compounds from garlic exert anti-carcinogenic potential target multiple pathways, inclusive of the cell cycle, apoptotic cell death and angiogenic pathway. The active form of alliinase enzyme can be stabilized into biocompatible materials such as alginate beads and layered double hydroxides. This review encompasses the multiple health effects of garlic and its bio-active constituents with references to health perspectives.

\section{References}

1. Tripathi K (2009) A Review -Garlic, the Spice of Life-(Part -I) Asian J Res Chem 2(1): 0974-4169.

2. Timbo BB, Ross MP, McCarthy PV, Lin CT (2006) Dietary supplements in a national survey: Prevalence of use and reports of adverse events. Am Diet Assoc 106(12): 1966-1974.

3. Jaber MA, Al Mossawi A (2007) Susceptibility of some multiple resistant bacteria to garlic extracts. Afr J Biotechnol 6(6): 771-776.

4. Rose P, Whiteman M, Moore PK (2005) Bioactive S-alk(en)yl cysteine sulfoxide metabolites inthe genus Allium, the chemistry of potential therapeutic agents. Nat Prod Rep 22(3): 351-368.

5. Lanzotti V (2006) The analysis of onion and garlic. J Chromatogr A 1112(1-2): 3-22.

6. De Martino A, Filomeni G, Aquilano K (2006) Effects of water garlic extracts on cell cycle and viability of HepG2 hepatoma cells. J Nutrit Biochem 17(11): 742-749.

7. Nencini C, Franchi GG, Cavallo F, Micheli L (2010) Protective Effect of Allium neapolitanum Cyr Versus Allium sativum L on Acute EthanolInduced Oxidative Stress in Rat Liver. J Med Food 13(2): 329-335.

8. Nencini C, Menchiari A, Franchi GG, Micheli L (2011) In vitro Antioxidant Activity of Aged Extracts of some Italian Allium Species. Plant Foods Hum Nutr 66(1): 11-16.

9. Park JH, Park YK, Park E (2009) Antioxidative and Antigenotoxic Effects of Garlic (Allium. sativum L.) Prepared by Different Processing Methods. Plant Foods Hum Nutr 64(4): 244-249.

10. Kim SH, Bommareddy A, Singh S (2011) Garlic constituent diallyltrisulfide suppresses $\mathrm{x}$-linked inhibitor of apoptosis protein in prostate cancer cells in culture and in vivo. Cancer Prev Res (Phila) 4(6): 897-906.

11. Choi YH, Park HS (2012) Apoptosis induction of U937 human leukemia cells by diallyltrisulfide induces through generation of reactive oxygen species. J Biomed Sci 19: 50.

12. Xiao J, Ching YP, Liong EC, Nanji AA, Fung MLet al. (2013) Garlic-derived S-allylmercaptocysteine is a hepato-protective agent in non-alcoholic fatty liver disease in vivo animal model. Eur J Nutr 52(1): 179-191.

13. Capasso A (2013) Antioxidant Action and Therapeutic Efficacy of Allium sativumL. Mole 18(1): 690-700.

14. Muninathan N, Ursula S, Prashanth T, Uma M, Kumar A (2014) Effect of paclitaxel along with di allyl sulfide on immuno competent cells, immune complexes and immunoglobulins changes in 7,12 Di Methyl Benz(A) anthracene induced skin cancer in Wistar rats. International J Med Res Health Sci 3(1): 155-160.
15. Das I, Acharya A, Saha T (2012) Protective effect of garlic in skin cancer. Human Health Handbooks no. 1(2): 300-317.

16. Cherng JM, Kuen Daw T, Perng DS, Wang JS, Wei CC, et al. (2011) Diallyl sulfide protects against ultraviolet B-induced skin cancers in SKH-1 hairless mouse, analysis of early molecular events in carcinogenesis. Photodermatol. Photoimmunol. Photomed 27(3): 138-146.

17. Mariani S, Lionetto L, Cavallari M, Tubaro A, Rasio D, et al. (2014) Communication Low Prostate Concentration of Lycopene Is Associated with Development of Prostate Cancer in Patients with High-Grade Prostatic Intraepithelial Neoplasia. Int J Mol Sci 15(1): 1433-1440.

18. Ozten Kandaş N, Bosland MC (2011) Chemoprevention of prostate cancer, Natural compounds, antiandrogens, and antioxidants-In vivo evidence. J Carcinog 10: 27.

19. Herman Antosiewicz A, Kim YA, Kim SH, Xiao D, Singh SV (2010) Diallyltrisulfide-induced G2/M phase cell cycle arrest in DU145 cells is asso- ciated with delayed nuclear translocation of cyclin-dependent kinase. Pharm Res 27(6): 1072-1079.

20. Arunkumar R, Sharmilaa G, Elumalaia P, Senthilkumara K, Banudevia S, et al. (2012) Effect of diallyl disulfide on insulin-like growth factor signaling molecules involved in cell survival and proliferation of human prostate cancer cells in vitro and in silico approach through docking analysis. Phytomedicine 19(10): 912-923.

21. Stan SD, Singh SV (2009) Transcriptional repression and inhibition of nuclear translocation of androgen receptor by diallyl trisulfide in human prostate cancer cells. Clin Cancer Res 15(15): 4895-903.

22. Xiao D, Zeng Y, Singh SV (2009) Diallyl trisulfide-induced apoptosis in human cancer cells is linked to checkpoint kinase 1-mediated mitotic arrest. Mol Carcinog 48(11): 1018-1029.

23. Xu YS, Feng JG, Zhang D, Zhang B, Luo M, et al. (2014) S-allylcysteine, a garlic derivative, suppresses proliferation and induces apoptosis in human ovarian cancer cells in vitro. Acta Pharmacologica Sinica 35(2): 267-274.

24. Rao MU, Sreenivasulu M, Chengaiah B, Reddy KJ, Chetty CM (2010) Herbal Medicines for Diabetes Mellitus A Review. Inter J Pharm Tech Res 2(3): 1883-1892.

25. Khan V, Najmi AK, Akhtar M, Aqil M, Mujeeb M, et al. (2012) A pharmacological appraisal of medicinal planst with antidiabetic potential. J Pharm Bioallied Sci 4(1): 27-42.

26. Ponnusamy M, Pari L (2011) Protective role of diallyl tetrasulfide on cadmium-induced testicular damage in adult rats: a biochemical and histological study. Toxicol Ind Health 27(5): 407-416.

27. Noor A, Vinay SB, \& Vijayalakshmi MA (2013) Current update on antidiabetic biomolecules from key traditional Indian medicinal plants. Curr Sci 104(6): 721-727.

28. Padiya R, Banerjee SK (2013) Garlic as an anti-diabetic agent, recent progress and patent reviews. Recent Pat. Food Nutr Agric 5(2): 105-127.

29. Osman MT, Adnan A, Bakar NS, Alashkham F (2012) The Potential Immunomodulatory Effect of allicin administration in autommune disease process of type 1 diabetes mellitus. Int J Pharm Pharm Sci 4(5): 440-444.

30. Liu CT, Wong PL, Lii CK, Hse H, Sheen LY (2006) Antidiabetic effect of garlic oil but not diallyl disulfide in rats with streptozotocin-induced diabetes. Food Chem Toxicol 44(8): 1377-1384.

31. Gaekwad V, Trivedi NA (2013) In vitro evaluation of antimicrobial effect of fresh garlic extract and its interaction with conventional antimicrobials against Escherichia coli isolates. International Journal of Current Research 5(1): 106-114.

32. Daka D (2011) Antibacterial effect of garlic (Allium sativum) on Staphyloccus aureus, An in vitro study. African Journal of Biotechnolgy 10(4): 666-669. 
33. Hindi NKK (2013) In vitro Antibacterial Activity of Aquatic Garlic Extract Apple Vinegar and Apple Vinegar-Garlic Extract combination. American Journal of Phytomedicine and Clinical Therapeutics 1(1): 2321-2748.

34. Hussein MM, Hassan AHW, Moussa IMI (2013) Potential use of allicin (garlic, Allium sativum Linn, essential oil) against fish pathogenic bacteria and its safety for monosex Nile tilapia (Oreochromisniloticus). Journal of Food and Agriculture Environment 11(1): 696-699.

35. Qidwai, W, Ashfaq T (2013) Role of Garlic Usage in Cardiovascular Disease Prevention, An Evidence-Based Approach. Evidence-Based Complementary and Alternative Medicine Pp: 9.

36. Thomson M, Mustafa M, Ali M (2000) Thromboxane-B (2) levels in serum of rabbits receiving a single intravenous dose of aqueous extract of garlic and onion. Prostaglandins Leukot Essent Fatty Acids 63(4): 217-221.

37. Sener G, Sakarcan A, Yegen BC (2007) Role of garlic in the prevention of ischemia-reperfusion injury. Molecular Nutrition \& Food Research 51(11): 1345-1352.

38. Kempaiah RK, Srinivasan K (2005) Influence of dietary spices on the fluidity of erythrocytes in hypercholesterolaemic rats. British Journal of Nutrition 93(1): 81-91.

\section{ISSN: 2574-1241}

DOI: 10.26717/BJSTR.2019.15.002721

Muhammad Hanif Mughal. Biomed J Sci \& Tech Res

cC (i) This work is licensed under Creative

Submission Link: https://biomedres.us/submit-manuscript.php
39. Wu CC, Sheen LY, Chen HW, Tsai SJ, Lii CK (2001) Effects of organosulfur compounds from garlic oil on the antioxidation system in rat liver and red blood cells. Food and Chemical Toxicology 39(6): 563-569.

40. Yadav RK, Verma NS (2004) Effects of garlic (Allium sativum) extract on the heart rate, rhythm and force of contraction in frog: a dose-dependent study. Indian Journal of Experimental Biology 42(6): 628-631.

41. Chandrashekar PM, Prashanth KV, Venkatesh YP (2011) Isolation, structural elucidation and immunomodulatory activity of fructans from aged garlic extract. Phytochemistry 72(2-3): 255-264.

42. Lang A, Lahav M, Sakhnini E, Barshack I, Fidder HH (2004) Allicin inhibits spontaneous and TNF-alpha induced secretion of proinflammatory cytokines and chemokines from intestinal epithelial cells. Clinical Nutrition 23(5): 1199-1208.

43. Wedemeyer J, Galli SJ (2000) Mast cells and basophils in acquired immunity. British Medical Bulletin 56(4): 936-55.

44. Yoo JM, Sok DE, Kim MR (2014) Anti-Allergic Action of Aged Black Garlic Extract in RBL- $2 \mathrm{H}_{3}$ Cells and Passive Cutaneous Anaphylaxis Reaction in Mice. Journal of Medicinal Foods 17(1): 92-102.

$\begin{array}{ll}\text { BIOMEDICAL } & \text { Assets of Publishing with us } \\ \text { RESEARCHES } & \text { - Global archiving of articles } \\ & \text { - Immediate, unrestricted online access } \\ & \text { - Rigorous Peer Review Process } \\ \end{array}$

